\title{
Alternativa de reciclagem de resíduos de espuma rígida de poliuretano com ABS
}

\author{
BOM, R.P. ${ }^{\mathrm{I}}$; \\ ${ }^{\text {I }}$ Universidade do Estado de Santa Catarina - UDESC - Centro de Ciências Tecnológicas - CCT. \\ Depto. Enga. Mecânica, Campus Universitário Avelino Marcante, B. Bom Retiro, CEP 89.223-100, Joinville, \\ $\mathrm{SC}$, Brasil. \\ e-mail: dem2rpb@joinville.udesc.br
}

\section{RESUMO}

Este trabalho tem como um dos objetivos realizar misturas de ABS/PUR com diferentes concentrações de PUR. Os resíduos de PUR são provenientes do processo de fabricação de refrigeradores e frízeres. A utilização deste tipo de resíduo é devido ao problema ambiental gerado com o descarte do material. A homogeneização de cada mistura foi feita com uma máquina extrusora monorosca. Uma parte do material extrudado e granulado foi utilizada para a realização de ensaios de Índice de Fluidez (IF) e outra parte foi utilizada no processo de moldagem por injeção, sendo injetados corpos de prova para a determinação da massa específica e alguns exemplares de peça técnica. Os resultados dos ensaios de índice de fluidez foram transformados inicialmente em vazão volumétrica, para isto foram utilizados os valores de massa específica determinada para as respectivas misturas. Posteriormente, por meio de equações reológicas foi calculada a viscosidade das diferentes misturas a $220^{\circ} \mathrm{C}$, sobre os pontos foi interpolada uma curva reológica para cada caso. Foram realizados ensaios de tração nos corpos de prova injetados com diferentes concentrações, determinou-se que o módulo de elasticidade aumenta linearmente com o aumento da concentração de PUR e a tensão máxima suportada pelo material decresce com o incremento de PUR. Determinou-se que o aumento da viscosidade das misturas provocou variações no processo de injeção, mesmo assim, foi possível injetar diferentes lotes de peças técnicas. Considerando as propriedades mecânicas e reológicas obtidas para as misturas pôde-se concluir que a fabricação de alguns tipos de componentes pode ser viável.

Palavras chaves: Índice de fluidez, viscosidade, propriedade mecânica, massa específica.

\section{Alternative of recycling residues of polyurethane rigid foam with ABS ABSTRACT}

The main aim of this paper is to carry out ABS/PUR mixtures with different concentrations of PUR. The PUR residues originate from the manufacture of refrigerators and freezers. The use of this type of residue generates environment problems when discharging this material. The homogenization of each mixture was made with a single screw extruder. A part of the extruded and granulated material was used for the accomplishment of assays of Melt Flow Index (MFI) and another part was used in the process of moulding specimens by injection, in order to determine the specific mass and also obtain some samples of technical parts. The results of the assays of fluidity index had been initially transformed into volumetric outflow. For this to happen, the values of determined specific mass for the respective mixtures had been used. Later, by means of rheologic equations the the viscosity of the different mixtures was calculated at $220^{\circ} \mathrm{C}$. A rheologic curve was interpolated on the points for each case. Assays of traction had been carried out in the specimens injected with different concentrations, which determined that the modulus of elasticity increases linearly with the increase of the PUR concentration and the maximum tension supported by the material decreases with the PUR increment. It was determined that the increase of the viscosity of the mixtures provoked variations in the injection process, even though, it was possible to inject different lots of technical parts. Considering the mechanical and rheological properties obtained for the mixtures it could be concluded that the manufacture of some types of components could be viable.

Keywords: Index of fluidity, viscosity, mechanical property, specific mass. 


\section{INTRODUÇÃO}

Um dos grandes problemas atuais é a destinação final de materiais que não podem mais ser reutilizados no processo de origem. Um exemplo deste problema é a espuma rígida de poliuretano (PUR) utilizada como elemento de isolamento térmico e estrutural na fabricação de refrigeradores e frízeres [1]. Este material é um termorrígido e sua estrutura na forma final quando expandido é composta de células fechadas. A origem de resíduos deste material é diversificada dentro da indústria, podendo ser de peças defeituosas, de equipamentos que foram testados e posteriormente destruídos, de bancadas de ensaios e desenvolvimento, de tray out de moldes etc. Entretanto, com a vigência de novas leis [2] que obrigarão os fabricantes a reciclarem o produto no final de sua vida útil farão aumentar significativamente a quantidade de resíduos de PUR a serem reciclados.

Procurando uma saída para o problema, algumas iniciativas de pesquisa foram realizadas. Um exemplo de trabalho feito foi a mistura de PUR moído com cimento para obter blocos de cimento, como resultado interessante, obteve-se redução de peso e melhoria da condutividade térmica, entretanto, a propriedade mecânica a compressão ficou a desejar [3] . Outro trabalho na mesma linha de pesquisa procurou incorporar o PUR com granulometria específica adicionando até $10 \%$ de PUR, para concentrações de 5\% de PUR, foi possível obter resistências que permitiram a aprovação de blocos para fins estruturais [4]. Misturas de resíduos de PUR com resíduos sólidos provenientes de processos de tratamento de efluentes da indústria têxtil foi utilizado na composição de argamassas para revestimento em chapas metálicas, processo utilizado no revestimento de pias [5] . Outro trabalho foi à incorporação de PUR em resina termoplástica de polipropileno enxertado com anidrido maleico como agente compatibilizante $[\underline{6}, \underline{7}, \underline{8}]$. Mais recentemente, foi incorporado o PUR em materiais termoplásticos como, PS, PSAI e ABS. Um dos objetivos desta última foi de realizar as misturas e determinar a influencia do acréscimo de PUR sobre as propriedades mecânicas das misturas e correlaciona-las com a resina pura [1]. Uma ênfase maior sobre a reologia das misturas de PSAI com resíduos de espuma rígida de PU foi realizado por BOM [9]. Este trabalho tem por objetivo caracterizar por meio de ensaio mecânico: a variação da tensão máxima, a deformação e o módulo de elasticidade para diferentes misturas de ABS/PUR. Também serão determinadas a massa específica das misturas e o Índice de Fluidez. A partir do IF das misturas e por meio de equações reológicas foram calculadas as viscosidades para o material puro e para as diferentes misturas e sobre os pontos do gráfico viscosidade $\mathrm{x}$ taxa de cisalhamento foram interpoladas as respectivas curvas reológicas. Uma análise termogravimétrica foi realizada para determinar se os resíduos de espuma rígida de PUR são estáveis nas temperaturas de processamento. Por último, foram apresentados os resultados obtidos na moldagem por injeção de peças técnicas utilizadas no processo de fabricação de refrigeradores.

\section{MATERIAIS E MÉTODOS}

As misturas foram realizadas com o copolímero de acrilonitilo-estireno-butadieno (ABS) da Bayer com nome comercial de Lustran ABS M202AS e com resíduos de espuma rígida de poliuretano, moído, seco e peneirados em malha $2 \times 2 \mathrm{~mm}$. O resíduo é proveniente da indústria Multibrás S.A. Eletrodomésticos, a qual utiliza espuma rígida de PUR como isolante térmico e componente estrutural de gabinetes e portas isoladas que compõem refrigeradores e frízeres. Para realizar as misturas com diferentes concentrações de PUR, foram inicialmente preparadas as concentrações em massa e misturadas dentro de sacos plásticos. A mistura foi processada com uma extrusora monorosca e obteve-se o granulado. Em alguns casos foi necessário adicionar em partes a espuma rígida e repassar o material na máquina extrusora. Parte do material granulado foi utilizada para o ensaio de IF e utilizou-se um plastômetro Melt Flow T.Q. CEAST 6841/048, o ensaio de IF foi realizado conforme norma ASTM D 1238-99, temperatura de $220^{\circ} \mathrm{C}$ e massas de 2,$12 ; 3,77$ e 4,$97 ; 6,80 ; 8,45 ; 10,02$ e $11,77 \mathrm{Kg}$.

Para a obtenção de corpos de prova para a determinação da massa específica e para os ensaios de tração, foi utilizada uma máquina injetora da marca Battenfeld, com as seguintes características: força de fechamento de 140 ton. e capacidade de injeção de $125 \mathrm{~g}$ de PS. Os parâmetros do processo de injeção foram: tempo de injeção igual a $5 \mathrm{~s}$, pressão de injeção de 50 até 65 bar, tempo de recalque de $2 \mathrm{~s}$, pressão de recalque de 15 bar e tempo de resfriamento de $35 \mathrm{~s}$.

A massa específica do material foi determinada pelo processo de imersão e variação do volume, a temperatura de $23^{\circ} \mathrm{C}$, conforme norma ASTM D792-86, onde foram utilizados os corpos de prova obtidos por moldagem por injeção. Foi utilizada a curva PVT do material como referência.

Foi utilizada a curva reológica de Carreau-WLF [10] para o ABS com IF de $32 \mathrm{~g} / 10 \mathrm{~min}$ a $\mathrm{T}=220^{\circ} \mathrm{C}$ e carga de $10 \mathrm{Kg}$ e seus respectivos parâmetros.

Os ensaios de tração foram realizados com uma máquina universal MTS SINTECH 10/D, utilizando célula de carga de $5.000 \mathrm{~N}$ e extensômetro de $25 \mathrm{~mm}$ de abertura inicial e com $100 \%$ de abertura total igual a $50 \mathrm{~mm}$. A velocidade de ensaio foi de $5 \mathrm{~mm} / \mathrm{min}$ e foram realizados com 5 ensaios de cada amostra. 


\section{RESULTADOS}

$\mathrm{Na}$ Figura 1 estão representados os resultados da massa específica determinada pelo método de imersão para as diferentes misturas. $\mathrm{O}$ valor da massa específica para o ABS puro obtido experimentalmente a $23^{\circ} \mathrm{C}$ está coerente com o resultado encontrado na literatura, menos de $1,42 \%$ de erro se comparado com o resultado fornecido pelo fabricante, valor semelhante pode ser obtido pelo prolongamento da reta média, para concentração nula conforme indicado na Figura 1. À medida que a concentração de espuma rígida aumenta, a massa específica aumenta. Uma interpolação linear foi realizada para descrever o comportamento da variação da massa específica em função do acréscimo de resíduos de espuma rígida de PUR, as barras de erro representam o desvio padrão das medidas.

A partir da curva PVT do ABS [11] foi determinado que a massa específica à temperatura de $220^{\circ} \mathrm{C}$ é aproximadamente $0,96702 \mathrm{~g} / \mathrm{cm}^{3}$. Tomando como base a massa específica do ABS a $220^{\circ} \mathrm{C}$ e transladando a reta da variação da massa específica de $23^{\circ} \mathrm{C}$ para $220^{\circ} \mathrm{C}$, então, a massa específica das misturas a $\mathrm{T}=220^{\circ} \mathrm{C}$ podem ser representadas pela equação da reta que está indicada dentro da Figura 1, reta inferior, com esta informação pode-se transformar o fluxo de massa determinado a partir dos ensaios de IF em vazão.

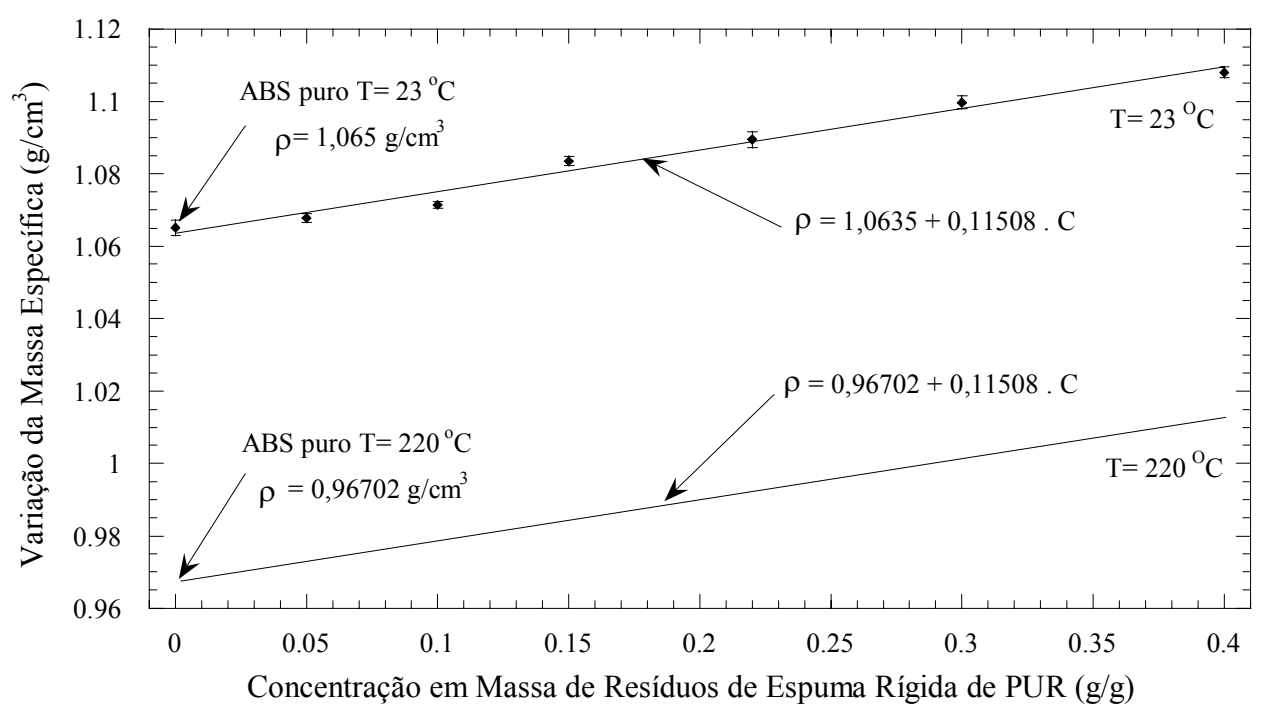

Figura 1: Variação da massa específica $(\rho)$ em função da variação da concentração em massa de espuma rígida de poliuretano (C) dentro da matriz de ABS.

Na Tabela 1 estão indicados os valores dos Índices de Fluidez determinados para as diferentes misturas e para as diferentes cargas impostas.

Tabela 1: Valores de Índice de Fluidez para o ABS puro e misturas com PUR

\begin{tabular}{|c|c|c|c|c|c|c|c|c|}
\hline & \multirow{2}{*}{$\begin{array}{l}\text { Massa da } \\
\text { Carga (g) }\end{array}$} & \multicolumn{7}{|c|}{ Concentração em Massa de PUR (g/g) } \\
\hline & & 0,00 & 0,05 & 0,10 & 0,15 & 0,22 & 0,30 & 0,40 \\
\hline \multirow{7}{*}{ 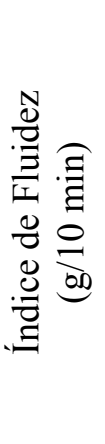 } & $2.123,82$ & 2,0960 & & & & & & \\
\hline & $3.773,00$ & 5,7340 & & & & & & \\
\hline & $4.966,58$ & 9,8820 & 8,8240 & 6,4480 & 4,7360 & 3,6290 & 2,5820 & 1,8325 \\
\hline & $6.800,40$ & 17,356 & & & & & & \\
\hline & $8.449,58$ & 25,806 & 20,700 & 15,3480 & 11,5320 & 10,4120 & 7,9520 & 5,3720 \\
\hline & $10.017,01$ & 34,812 & & & & & & \\
\hline & $11.773,83$ & 48,228 & 41,148 & 30,1080 & 22,8480 & 18,2520 & 14,1840 & 9,6400 \\
\hline
\end{tabular}


Na Figura 2, estão representados os IF das misturas em função das cargas impostas no ensaio e respectivas concentrações. Como pode ser observado nas curvas da figura abaixo, com o aumento da pressão no barril do plastômetro aumenta a vazão, portanto, a fluidez é maior. Com o aumento da concentração de PUR a viscosidade da mistura aumenta e assim a fluidez diminui, como observado nas curvas da Figura 2. O erro na determinação do IF em relação ao valor obtido na referencia é de $8,79 \%$, entretanto, deve-se deixar claro que o procedimento a ser realizado aqui irá corrigir as distorções de valores em relação a curva de viscosidade.

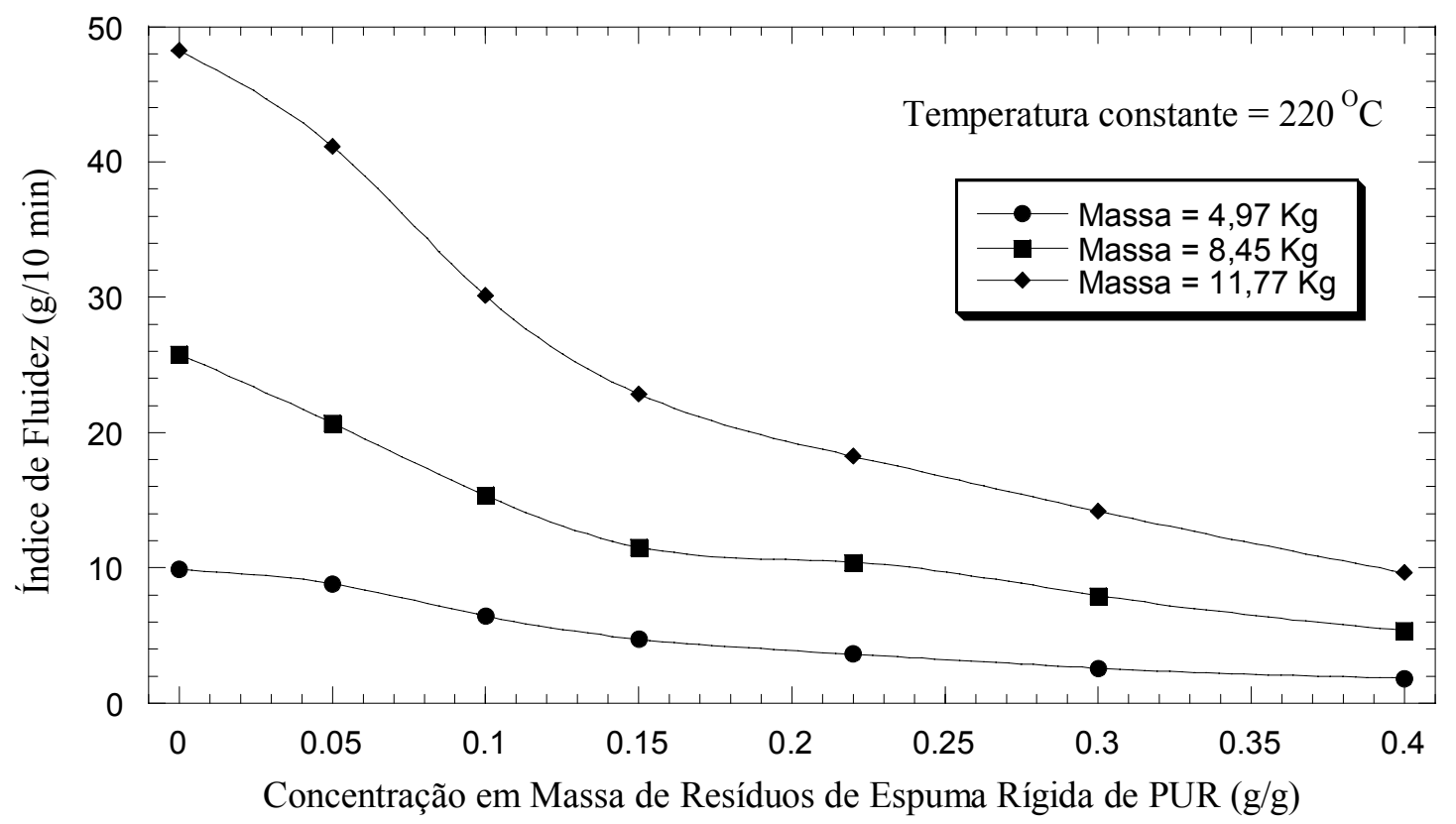

Figura 2: Variação do Índice de Fluidez em função da carga: •) 4,97 Kg; $\square$ ) 8,45 Kg; e •) 11,77 Kg) e da concentração em massa de PUR, T=220oC.

A Equação 1 permite realizar a conversão dos resultados de IF em Vazão (Q) [12], para isto é necessária a massa específica a $220^{\circ} \mathrm{C}$, os resultados dos ensaios de IF, na equação ( $\mathrm{K}^{\prime}$ ) é um coeficiente de conversão.

$$
\mathrm{IF}=\mathrm{K}^{\prime} \rho \mathrm{Q}
$$

Com a Equação 2 pode-se calcular a tensão de cisalhamento na parede $\left(\tau_{\mathrm{p}}\right)$ do canal do plastômetro, nesta equação $(\Delta \mathrm{P})$ é a pressão no barril, $(\mathrm{R})$ e $(\mathrm{L})$ são respectivamente o raio e o comprimento do canal [13, $\underline{14}, \underline{15}]$.

$$
\tau_{\mathrm{p}}=\frac{\Delta \mathrm{PR}}{2 \mathrm{~L}}
$$

Para calcular a taxa de cisalhamento real $(\dot{\gamma})$ em função da tensão de cisalhamento para um polímero termoplástico com comportamento pseudoplástico, deve-se determinar a vazão dentro do um cilíndrico com escoamento isotérmico a solução deste problema é dada pela Equação 3 que é conhecida pelo nome de equação de Rabinowitsch $[\underline{13}, \underline{15}, \underline{16}, \underline{17]}$.

$$
\dot{\gamma}=\frac{4 \mathrm{Q}}{\pi \mathrm{R}^{3}}\left(\frac{3}{4}+\frac{1}{4} \frac{\mathrm{dLnQ}}{\mathrm{dLn} \tau_{\mathrm{p}}}\right)
$$


O termo dLṇ $\tau_{\mathrm{p}} / \mathrm{dLnQ}$ é conhecido como índice de pseudoplasticidade (n) e para obter este valor é necessário realizar o gráfico da tensão de cisalhamento na parede $\left(\tau_{\mathrm{p}}\right)$ em função da variação da vazão $(\mathrm{Q})$ como representado na Figura 3, o valor do coeficiente angular das retas representam o índice (n). Dependendo da mudança de variável ao resolver a intergral da expressão da vazão (Q), pode-se chegar ao seguinte resultado $\mathrm{n}=\mathrm{dLn} \tau_{\mathrm{p}} / \mathrm{dLn} \dot{\gamma}_{\mathrm{a}}=\mathrm{dLn} \tau_{\mathrm{p}} / \mathrm{dLnQ}[\underline{13}, \underline{16}]$.

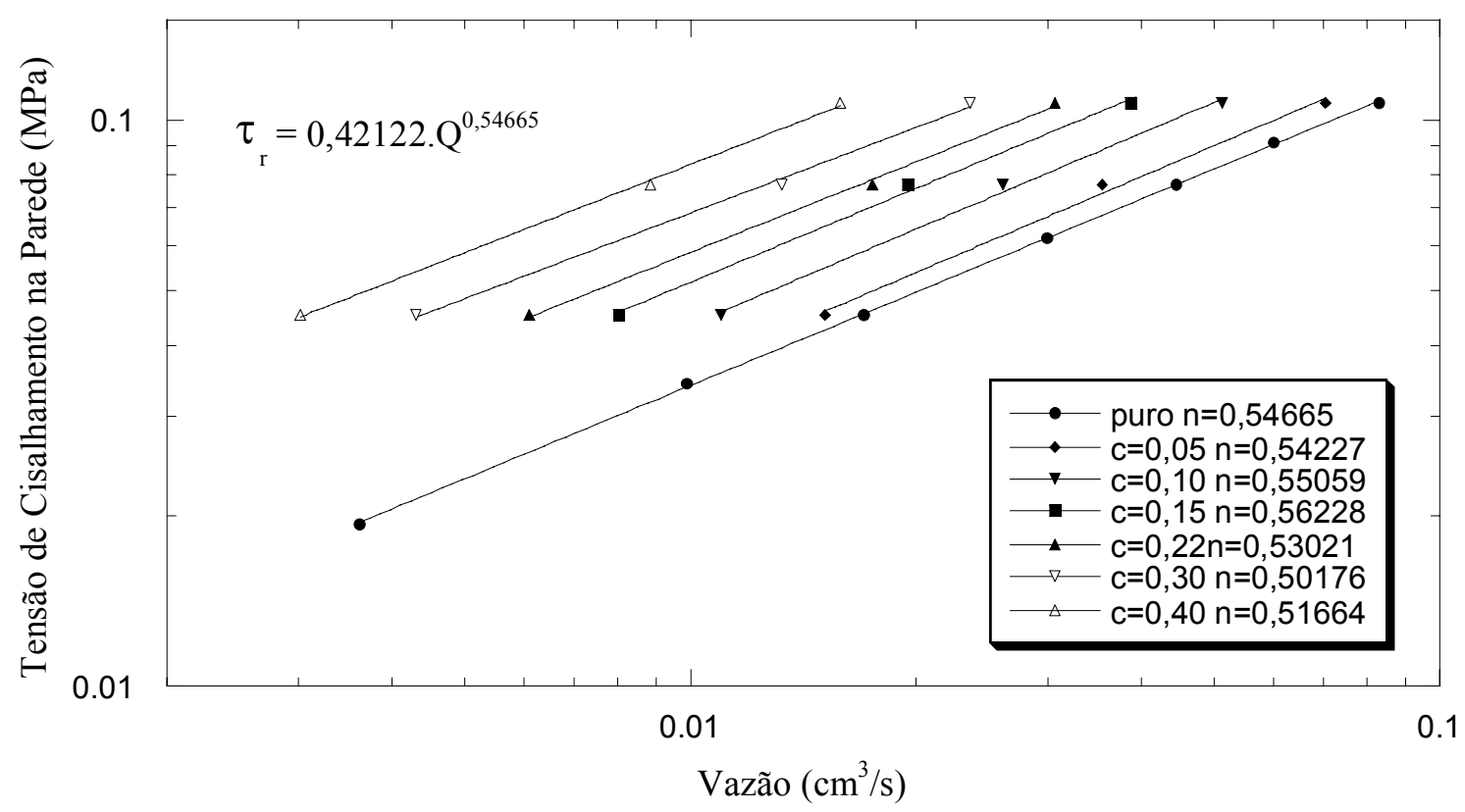

Figura 3: Variação do Índice de escoamento (n) para misturas de ABS/PUR. • ) resina virgem; •) $\mathrm{C}=0,05$ $\mathrm{g} / \mathrm{g} ; \boldsymbol{\square}) \mathrm{C}=0,10 \mathrm{~g} / \mathrm{g} ; \boldsymbol{\nabla}) \mathrm{C}=0,15 \mathrm{~g} / \mathrm{g} ; \boldsymbol{\Delta}) \mathrm{C}=0,22 \mathrm{~g} / \mathrm{g} ; \nabla) \mathrm{C}=0,30 \mathrm{~g} / \mathrm{g}$ e $\triangle) \mathrm{C}=0,40 \mathrm{~g} / \mathrm{g}$.

$\mathrm{Na}$ documentação técnica fornecida pela Bayer [10] pode-se encontrar a Equação 4 e seus respectivos parâmetros que descrevem a variação da viscosidade do ABS em função da taxa de cisalhamento.

$$
\eta(\dot{\gamma}, \mathrm{T})=\frac{\mathrm{K}_{1} \alpha_{\mathrm{T}}}{\left(1+\mathrm{K}_{2} \dot{\gamma} \alpha_{\mathrm{T}}\right) \mathrm{K}_{3}}
$$

A Equação 5 determina o valor do parâmetro $\alpha_{\mathrm{T}}$ para a temperatura desejada, assim a curva da viscosidade em função da taxa de cisalhamento, dada pela Equação 4 pode ser determinada para qualquer temperatura. Os parâmetros das Equações 4 e 5 obtidos na literatura estão indicados na Tabela 2.

$$
\lg \alpha_{\mathrm{T}}=\frac{8,86 \cdot\left(\mathrm{K}_{4}-\mathrm{K}_{5}\right)}{101,6+\mathrm{K}_{4}-\mathrm{K}_{5}}-\frac{8,86 \cdot\left(\mathrm{T}-\mathrm{K}_{5}\right)}{101,6+\mathrm{T}-\mathrm{K}_{5}}
$$

Tabela 2: Parâmetros utilizados nas Equações 4 e 5.

\begin{tabular}{|c|c|c|c|c|c|c|}
\hline $\begin{array}{c}\mathrm{K}_{1} \\
(\text { Pa.s })\end{array}$ & $\begin{array}{c}\mathrm{K}_{2} \\
(\mathrm{~s})\end{array}$ & $\mathrm{K}_{3}$ & $\begin{array}{c}\mathrm{K}_{4} \\
\left({ }^{\circ} \mathrm{C}\right)\end{array}$ & $\begin{array}{c}\mathrm{K}_{5} \\
\left({ }^{\circ} \mathrm{C}\right)\end{array}$ & $\begin{array}{c}\alpha_{\mathrm{T}} \\
\left({ }^{\circ} \mathrm{C}\right)\end{array}$ \\
\hline $4,446 \mathrm{E} 2$ & $9,066 \mathrm{E}-3$ & $6,158 \mathrm{E}-1$ & 260 & 129 & 6,365 & 220 \\
\hline
\end{tabular}


Na Figura 4 está representada a solução obtida por meio das Equações 4 e 5 para o polímero puro a temperatura de 193,5 e $220^{\circ} \mathrm{C}$. Para se determinar a viscosidade das misturas é necessário se conhecer a tensão de cisalhamento real $(\tau)$, para isto é preciso determinar o coeficiente de correção de Bagley $(\mathrm{e})$.

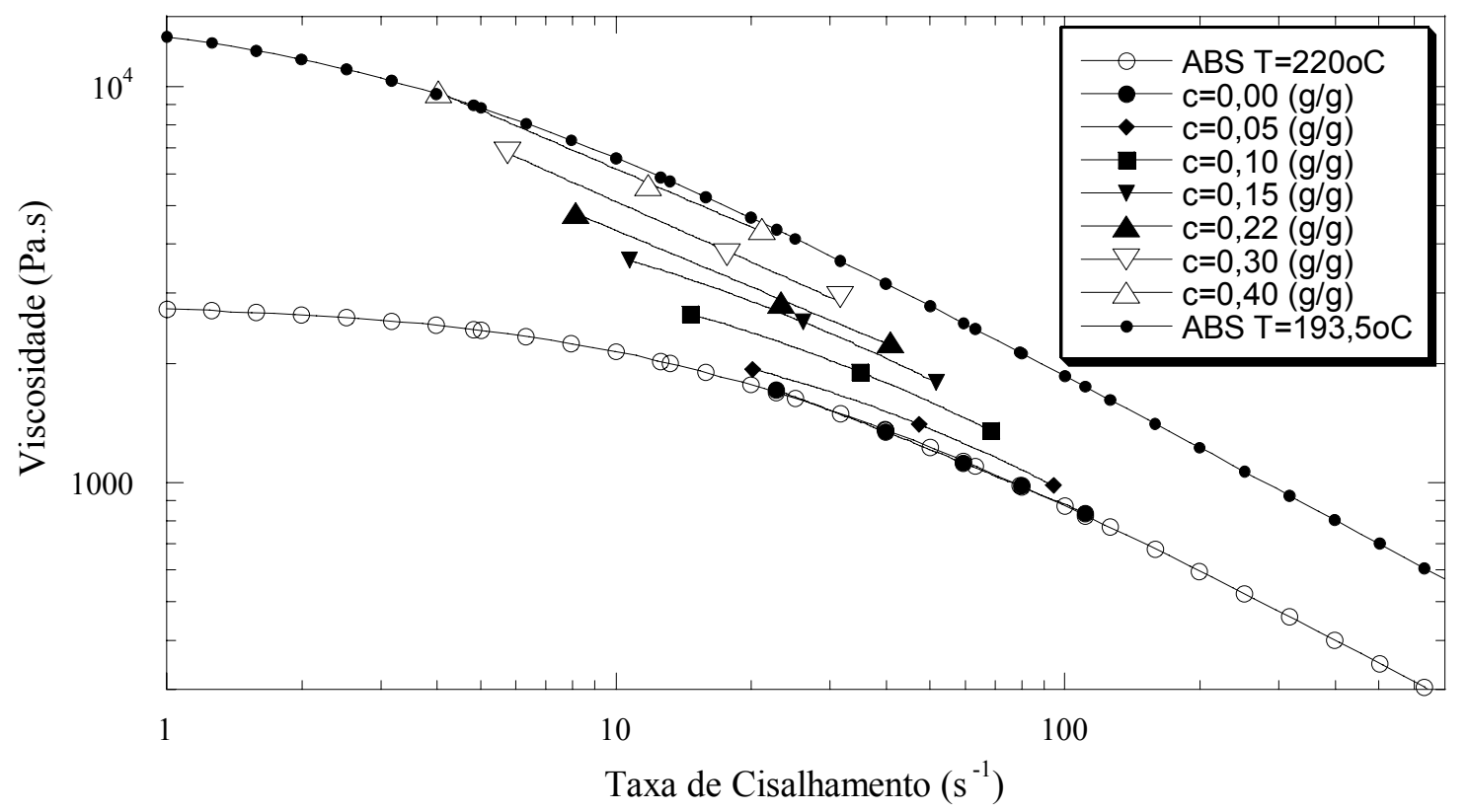

Figura 4: Variação da viscosidade em função da variação da taxa de cisalhamento, para o ABS puro, curva fornecida pelo fabricante para temperaturas de •) $\mathrm{T}=193,5^{\circ} \mathrm{C}$ e $\mathrm{O}$ ) $200^{\circ} \mathrm{C}$. Viscosidade a partir de medidas de Índice de Fluidez: - ) resina virgem. Misturas com PUR: •) $\mathrm{C}=0,05 \mathrm{~g} / \mathrm{g}$; $\boldsymbol{\square}$ ) $\mathrm{C}=0,10 \mathrm{~g} / \mathrm{g}$; ) $\mathrm{C}=0,15 \mathrm{~g} / \mathrm{g}$; А ) $\mathrm{C}=0,22 \mathrm{~g} / \mathrm{g} ; \nabla) \mathrm{C}=0,30 \mathrm{~g} / \mathrm{g}$ e $\triangle) \mathrm{C}=0,40 \mathrm{~g} / \mathrm{g}$.

A Equação 6 descreve a viscosidade em função da tensão de cisalhamento real $(\tau)$ e da taxa de cisalhamento real $(\dot{\gamma})$. Utilizando os mesmos valores da taxa de cisalhamento obtidos pela Equação 3 e a viscosidade calculada por meio da Equação 4 e 5, calcula-se a tensão de cisalhamento real.

$$
\eta=\frac{\tau}{\dot{\gamma}}
$$

Aplicando o resultado da Equação 6 na Equação 7 e inserindo os respectivos valores da pressão no barril do plastômetro e os valores do raio (R) e do comprimento do canal (L), pode-se calcular o termo de correção de Bagley (e) $[\underline{13}, \underline{14}]$.

$$
\tau=\frac{\Delta \mathrm{P}}{2\left(\frac{\mathrm{L}}{\mathrm{R}}+\mathrm{e}\right)}
$$

Uma vez determinado o valor de (e) por meio da Equação 7 para o ABS puro em função da pressão do barril, e tomando o valor médio dos experimentos como sendo e=2,03 e aplicando este valor novamente na Equação 7, pode-se determinar a viscosidade das misturas em função da taxa de cisalhamento real []], como indicado na Figura 4. A conclusão é que o aumento da concentração de PUR nas misturas aumenta significativamente a viscosidade em baixas taxas de cisalhamento. Mesmo a baixas taxas de deformação percebe-se que as misturas apresentam um comportamento não newtoniano, ou seja, diminuem a viscosidade 
com o aumento da taxa de cisalhamento. As viscosidades das misturas com concentração de $0,40 \mathrm{~g} / \mathrm{g}$ são equivalentes a viscosidade do ABS puro a uma temperatura de $193,5^{\circ} \mathrm{C}$.

Foram realizados ensaios de tração nos corpos de prova do ABS puro e das misturas, na Figura 5 estão representadas as respectivas variações da tensão máxima e de ruptura em função da concentração de PUR. Foram realizados 5 ensaios de tração para cada mistura, nos gráficos estão representadas as médias e os respectivos desvios padrão. Pode ser observado que para o material puro existe uma variação maior entre as duas tensões, isto pode ser devido a um maior alongamento após atingir a tensão máxima.

Aparentemente a incorporação de PUR na matriz de ABS inibe a diferença entre tensões fazendo com que a relação entre as duas seja praticamente constante a partir da mistura com $0,05 \mathrm{~g} / \mathrm{g}$ de PUR.

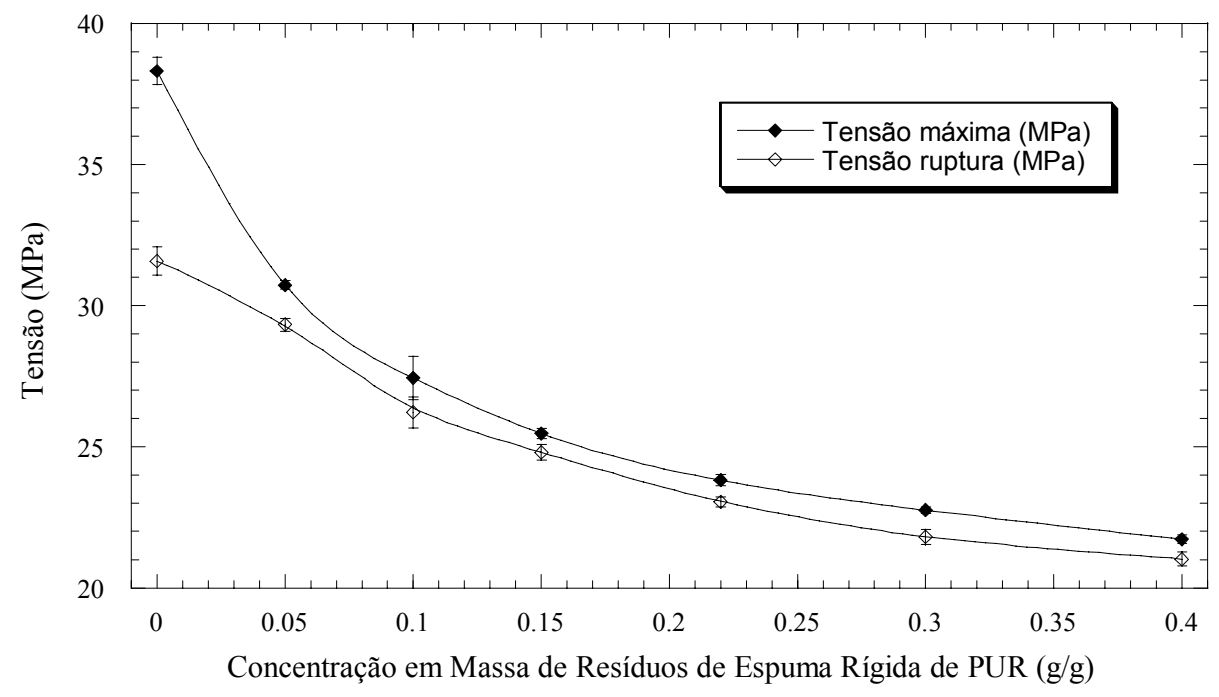

Figura 5: Variação da $\bullet$ ) tensão máxima e da $\diamond)$ tensão de ruptura em função da concentração de PUR nas misturas.

Na Figura 6 estão representadas as curvas de deformação máxima e de ruptura obtidas para as respectivas tensões, máxima e de ruptura. Como pode ser observada a relação entre as deformações é maior para o material puro e vai diminuindo com o aumento da concentração de PUR e para a concentração de 0,40 $\mathrm{g} / \mathrm{g}$ a diferença entre as deformações é muito pequena até atingir a ruptura.

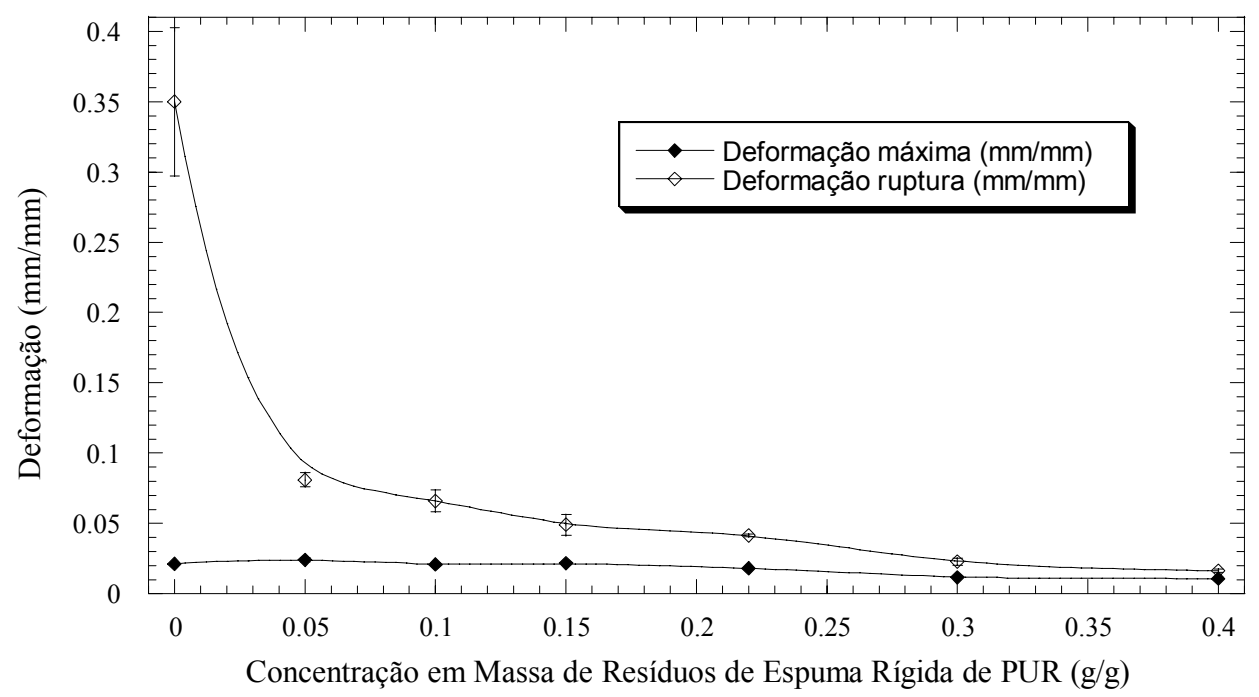

Figura 6: Variação da $\diamond$ ) deformação máxima e da $\diamond)$ deformação na ruptura em função da concentração de PUR nas misturas. 
Na Figura 7 está representada a variação do módulo de elasticidade em função da concentração das misturas. O valor determinado para o módulo de elasticidade do ABS puro apresenta a mesma ordem de grandeza do valor fornecido pelo fabricante. A incorporação de PUR na matriz de ABS aumentou a rigidez e este aumento pode ser representado linearmente, a variação entre o material puro e a concentração de 0,40 $\mathrm{g} / \mathrm{g}$ não foi superior a $10 \%$.

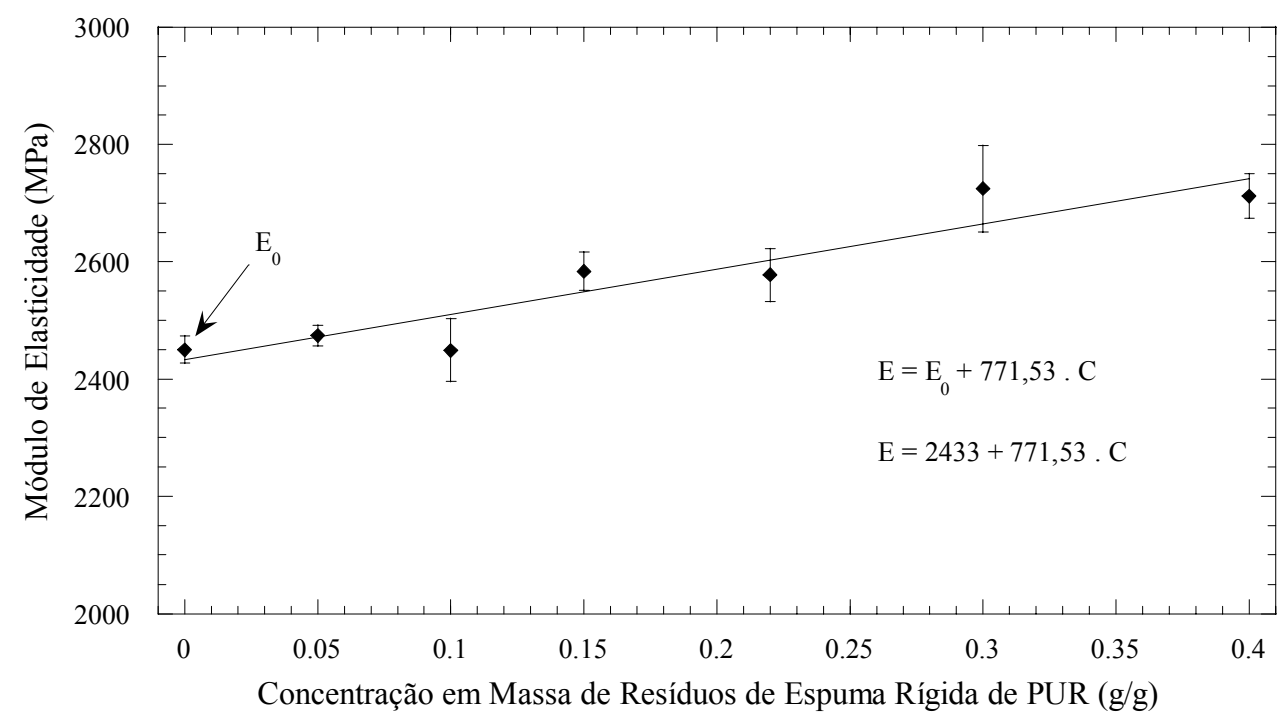

Figura 7: Variação do módulo de elasticidade em função da concentração de PUR nas misturas.

Os parâmetros determinados por meio de ensaios de tração indicam que as misturas analisadas apresentam valores de tensão máxima, deformação e módulo de elasticidade, compatíveis com os valores utilizados na fabricação de peças técnicas.

Foi realizado um ensaio de termogravimetria (TG) somente com o resíduo de PUR, foram utilizadas $20,659 \mathrm{mg}$ de material, o ensaio foi realizado da temperatura ambiente até $500^{\circ} \mathrm{C}$. A Figura 8 mostra o resultado obtido no ensaio. Como pode ser observada na curva de perda de massa, a variação de massa inicia a partir de $259,3^{\circ} \mathrm{C}$. Portanto, a espuma rígida de PU foi considerada com estável na temperatura de processamento.

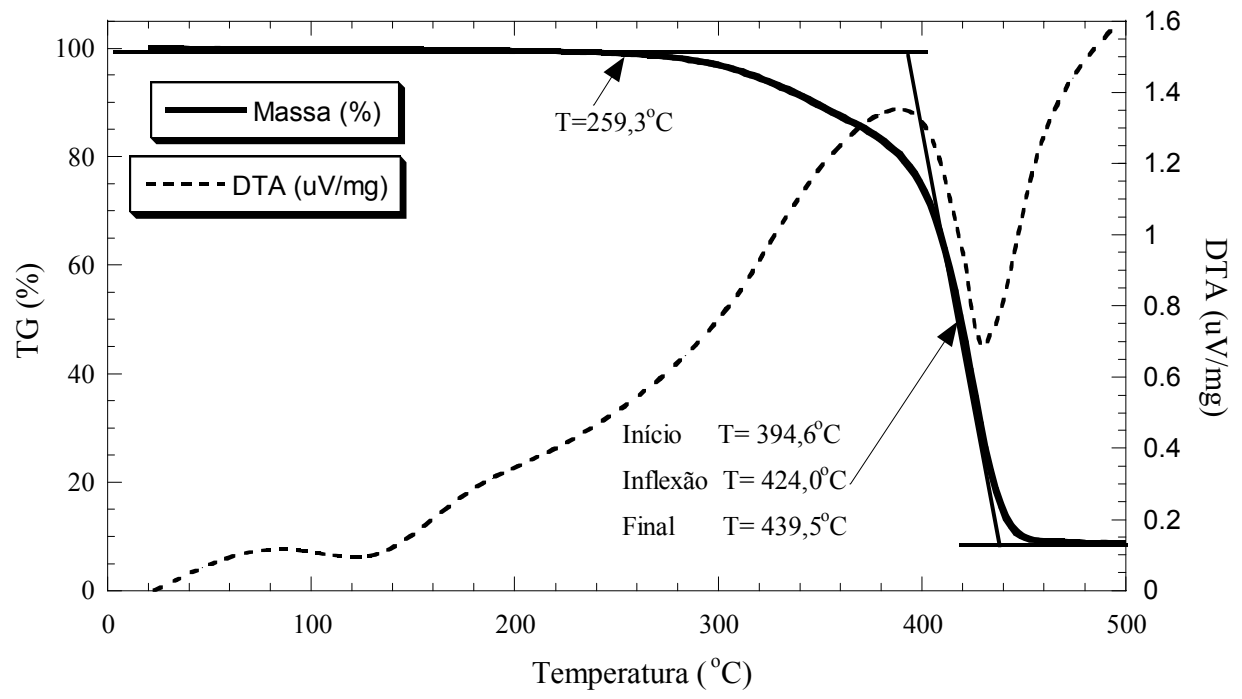

Figura 8: Ensaio de perda de massa (TG), para a espuma rígida de poliuretano.

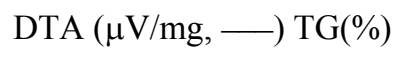


Na Figura 9 estão as fotografias das peças técnicas moldadas pelo processo de injeção. A escolha destas peças chamadas de difusores de poliuretano foi baseada no fato de serem peças que auxiliam uma determinada etapa do processo de fabricação de refrigeradores e que no final do processo ficam encobertas. Estas peças geralmente são fabricadas com material reciclado da própria indústria. As peças não apresentaram problemas de preenchimento e seu aspecto visual foi aprovado. A incorporação de PUR no ABS mudou gradualmente a coloração do material.

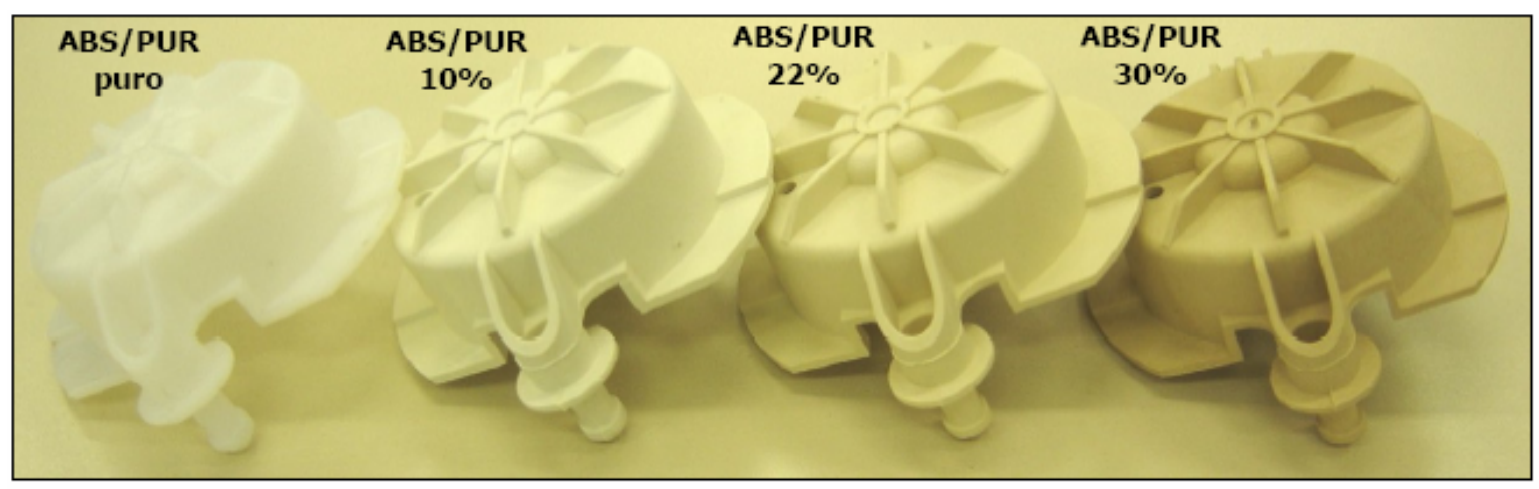

Figura 9: Exemplo de aplicação de misturas de ABS/PUR em peças técnicas.

\section{CONCLUSÃO}

No que diz respeito à realização das misturas, conclui-se que até uma concentração de $15 \%$ de PUR a incorporação é fácil de realizar. Entretanto, o espaguete que sai da extrusora é quebradiço.

Foi possível a partir de ensaios de IF determinar a viscosidade do ABS puro e das misturas por meio da utilização de equações reológicas. Pôde ser determinado que o incremento de resíduos de espuma rígida de PUR aumenta a viscosidade das misturas e as misturas apresentam ainda um comportamento não newtoniano a baixas taxas de cisalhamento.

O aumento de viscosidade das misturas refletiu diretamente nos parâmetros do processo de injeção, quanto maior a concentração maior foi à viscosidade e maior foi à pressão de injeção para obter corpos de prova e peças técnicas aprovadas sem defeitos por meio de inspeções visuais. Foram injetados lotes de peças técnicas com 10, 22 e 30\% de PUR. As peças apresentaram boa aparência e não apresentaram dificuldades para o preenchimento das cavidades do molde.

No que diz respeito às propriedades mecânicas as misturas apresentaram uma redução da tensão máxima em relação ao material puro chegando a $43 \%$ de perda para a concentração de $40 \%$ de PUR. A deformação máxima correspondente à tensão máxima não apresentou variações significativas. A adição de PUR diminuiu a fase de escoamento após as misturas atingirem a tensão máxima.

A rigidez das misturas aumentou de forma linear com o aumento da concentração de PUR, o aumento do módulo e elasticidade foi inferior a 10\% em relação ao ABS puro.

Conclui-se que a incorporação de PUR em ABS é uma alternativa viável e que pode ser realizada com a utilização de ABS reciclado da própria empresa. Esta alternativa não depende da quantidade de PUR disponível e sim aonde pode ser aplicado, desde que satisfaçam os requisitos necessários ao bom desempenho funcional da peça.

\section{REFERÊNCIAS BIBLIOGRÁFICAS}

[1] LUCKMANN, L., Reciclagem de resíduos de espuma rígida de poliuretano através da incorporação em polímeros termoplásticos, ABS, PSAI e PS. 168 f. Dissertação de M.Sc., Universidade do Estado de Santa Catarina - UDESC, Joinville, SC, Brasil, 2005.

[2] PIASKOWY, M.S., "Normas européias terão impacto significativo para exportadores, normas diretivas", Revista Meio Ambiente, v. 50, 2004.

[3] CARValho, C.A., Reutilização de Poliuretano na Construção Civil, Monografia de Conclusão de Curso em Engenharia Ambiental, Univille, Joinville, 2004. 
[4] SILQUEIRA, L.V.M., STRAMARI. M.R., FOLQUERAS, M.V., "Adição de poliuretano expandido para a confecção de blocos de concreto leve", Congresso Em Ciências de Materiais SULMAT, Joinville, SC, 2004.

[5] PEREIRA, R.L., Resíduos Sólidos Industriais: Uma Fonte Alternativa na Elaboração de materiais Cerâmicos de Baixa Densidade, Dissertação de M.Sc., Joinville, SC, 2002.

[6] BECKER, D., Blendas PP/PU: Estudo do efeito do agente compatibilizaste e reciclagem de resíduos de $P U$, Dissertação M.Sc., UFSC, Florianópolis, 2002.

[7] BECKER, D., ROEDER, J., OLIVEIRA, R.V.B., SOLDI, V., PIRES, A.T.N., "Caracterização de materiais obtidos a partir da adição de resíduos de poliuretano e compatibilizados em matriz de polipropileno", Congresso em Ciência de Materiais do Mercosul-SULMAT, Joinville, SC, 2002.

[8] BECKER, D., ROEDER, J., OLIVEIRA, R.V.B., SOLDI, V., PIRES, A.T.N., "Blend of thermosetting polyurethane waste with polypropylene: influence of compatibilizing agent on interface domains and mechanical properties", Polymer Testing, v. 22, n. 2, 2003.

[9] BOM, R.P., "Análise reológica de misturas de PSAI com resíduos de espuma rígida de poliuretano", Estudos tecnológicos, v. 3, n. 2, 2007.

[10] Bayer, Designation of material for set no. 033, Lustran $\mathrm{ABS}^{\circledR}$ M202AS, agosto, 2001.

[11] Programa Campus ${ }^{\circledR}$ 5.0, Bayer materialscience AG, abril, 2004.

[12] NAVARRO, R.F., "Relação entre o índice de fluidez e a viscosidade aparente de polímeros pseudoplásticos”, Anais do $2^{O}$ Congresso Brasileiro de Polímeros, pp. 763-766, São Paulo, 1993.

[13] AGASSANT, J-F. et al., La Mise en Forme des Matières Plastiques, 3 ed, Paris, Tec \& Doc Lavoisier, 1996.

[14] GROUPE FRANÇAIS D'ETUDES ET D’APPLICATIONS DES POLYMERES, Initiation à la Chimie et á la Physico-Chimie Macromoleculaires. Proprietes Physiques des Polymeres Mise em Oeuvre., v. 2, pp. 91-98.

[15] DETERRE, R. et al., Introduction aux Matériaux Polymères, Paris, Tec \& Doc Lavoisier, 1997.

[16] DETERRE, R. et al., Injection des Polymères simulation, optimisation et conception, Paris, Tec \& Doc Lavoisier, 2003.

[17] CASTRO, A.G. et al., Reologia e suas Aplicações Industriais, Coleção Ciência e Tecnologia, Lisboa, Instituto Piaget, 2001. 